\title{
Clinical and economic strategies in outpatient medical care during the COVID-19 pandemic
}

\author{
David Anthony Provenzano, ${ }^{1}$ B Todd Sitzman, ${ }^{2}$ Samuel Ambrose Florentino (D) ,' \\ Glenn A Buterbaugh ${ }^{3}$
}

Additional material is published online only. To view please visit the journal online (http://dx.doi.org/10.1136/ rapm-2020-101640).

'Pain Diagnostics and Interventional Care, Sewickley, Pennsylvania, USA

${ }^{2}$ Advanced Pain Therapy, Hattiesburg, Mississippi, USA ${ }^{3}$ Hand \& UpperEx Center, Wexford, Pennsylvania, USA

Correspondence to Dr David Anthony Provenzano, Pain Diagnostics and Interventional Care, Sewickley, PA 15143, USA davidprovenzano@hotmail.com

Received 27 April 2020 Revised 1 May 2020

Accepted 4 May 2020

Published Online First

31 May 2020

\section{Linked}

- http://dx.doi.org/10.1136/ rapm-2020-101629

Check for updates

(C) American Society of Regional Anesthesia \& Pain Medicine 2020. No commercial re-use See rights and permissions. Published by BMJ.

To cite: Provenzano DA, Sitzman BT, Florentino SA, et al. Reg Anesth Pain Med 2020:45:579-585

\section{ABSTRACT}

The COVID-19 pandemic has resulted in significant clinical and economic consequences for medical practices of all specialties across the nation. Although the clinical implications are of the utmost importance, the economic consequences have also been serious and resulted in substantial damage to the US healthcare system, including pain practices. Outpatient pain practices have had to significantly change their clinical care pathways, including the incorporation of telemedicine. Elective medical and interventional care has been postponed. For the most part, ambulatory surgical centers have had to cease operations. As patient volumes have decreased for non-emergent elective care, the financial indicators have deteriorated. This review article will provide insight into solutions to mitigate the clinical and economic challenges induced by COVID-19. Undoubtedly, the COVID-19 pandemic will have short-term and long-term implications for all medical practices and facilities. In order to survive, medical practices will need dynamic, operational, and creative strategic plans to mitigate the disruption in medical care and pathways for successful reintegration of clinical and surgical practice.

\section{INTRODUCTION}

COVID-19, caused by severe acute respiratory syndrome coronavirus 2, was initially reported in December 2019 in Wuhan City, China. ${ }^{1}$ In the USA, the first published reported case occurred on January 20, 2020 and involved a 35-year-old man in Snohomish County, Washington returning to the USA on January 15, 2020 after visiting his family in Wuhan, China. ${ }^{2}$ Since these initial reportings, the world has experienced a pandemic that has resulted in significant clinical morbidity and mortality. To date (April 30, 2020) the world has seen a total of $3,249,667$ confirmed cases with 232,936 total deaths. ${ }^{3}$ In the USA there has been a total of $1,067,289$ confirmed cases with 63,515 total deaths. ${ }^{3}$ Not only has the COVID-19 pandemic had devastating health effects, but it has also caused significant, adverse global, social, and economic consequences.

Society and the healthcare industry have experienced significant financial strains. Specifically, in medicine, drastic alterations have occurred in daily practice. First, healthcare providers, hospitals, and government leadership have displayed heroic efforts to meet the daily needs of the COVID-19 pandemic and limit the COVID-19 community spread. Second, there have been major changes in the delivery of non-emergent and elective care in hospitals, hospital outpatient departments (HOPDs), outpatient offices, and ambulatory surgical centers (ASCs). The delivery of outpatient pain care has been forced to undergo radical transformation since the pandemic began and shelter-in-place orders were instituted. The first shelter-in-place order occurred on March 16, 2020 in San Francisco, California. Specifically, in Louisiana and Pennsylvania, stay-at-home orders began on March 22 and 23, respectively. These shelterin-place and stay-at-home orders have severely restricted in-person encounters for non-emergent and elective medical and procedural care.

Here, we provide insight into the evolution of outpatient medical care during the COVID-19 pandemic with a focus on the clinical and economic consequences. In addition, we will examine possible solutions to mitigate the economic, clinical, and humanistic outcomes resulting from the COVID-19 pandemic, with specific attention to outpatient pain management care performed in the office and ASC settings.

\section{CLINICAL AND ECONOMIC CONSEQUENCES TO OUTPATIENT, NON-EMERGENT, AND ELECTIVE CARE}

In order to limit the community spread of COVID19 , to preserve healthcare system capacity, and to protect the welfare of healthcare providers and patients, access to non-emergent and elective care has been severely restricted during the pandemic. Elective and non-emergent surgeries, procedures, and in-person patient visits have been deferred. Specifically, the Centers for Medicare and Medicaid Services (CMS) developed a tiered framework to prioritize services. ${ }^{4}$ The recommendations for Tier 1 (low acuity treatment or service) and Tier 2 (intermediate acuity treatment or service) services were to postpone services including elective surgical procedures while still allowing patient interaction with a healthcare provider through telemedicine services. Most outpatient pain care is classified as a Tier 1 or Tier 2 service. In addition, most of the interventional pain procedures provided in the office, ASC, and HOPD settings fall under a Tier 1 or Tier 2 service. Outpatient elective services abruptly stopped in March and most ASCs ceased operations.

Contingency care plans were necessary to meet the healthcare demands of patients with nonemergent needs. Published chronic pain guidelines 
provided medical and interventional treatment algorithms. ${ }^{5-8}$ The guidelines included recommendations for general risk mitigation strategies and for therapeutic treatments including opioids, non-steroidal anti-inflammatory drugs, minimally invasive steroid injections, and implantable pain therapies during the COVID-19 pandemic.

Although the clinical consequences of COVID-19 are central to healthcare providers, the societal and healthcare economic consequences have been significant. In March, the US Bureau of Labor Statistics reported that unemployment rate rose to $4.4 \%$ and total non-farm payroll employment decreased by $701,000 .^{9}$ The number of unemployed persons rose by 1.4 million. In addition, the number of persons employed part-time for economic reasons increased by 1.4 million. The economic data continued to worsen throughout April. On April 23, 2020 the US weekly jobless claims reached 4.4 million, bringing the last 5 weeks total to more than 26 million. ${ }^{10}$ This 5 -week total for job losses surpassed all of the job gains that have occurred since the great recession of 2008.

Even though employment within leisure and hospitality jobs accounted for $65 \%$ of the decrease in the March non-farm payroll employment, notable declines also occurred in the healthcare and social assistance sectors. ${ }^{9}$ Employment in healthcare and social assistance programs fell by 61,000 jobs, with significant losses occurring in dentist and physician offices. These numbers are in stark contrast to the prior 12 months during which healthcare employment had grown by 374,000 jobs. Multiple national news outlets documented the rapid decline in employment in hospitals, ASCs, and doctors' office sectors associated with non-emergent care (eg, diagnostics, office visits, surgical procedures). ${ }^{11-14}$

Physician practice viability in the hospital and private sectors has also been stressed during the COVID-19 pandemic by the drastic decrease in elective outpatient care. Currently in the USA, less than $50 \%$ of all practices are physician-owned. Specifically in 2018, physician owners accounted for approximately $46 \%$ of physician practice arrangements. ${ }^{15}$ In March and April, the American Medical Association in collaboration with additional societies (eg, American Society of Anesthesiologists, American Academy of Ophthalmology, and American Association of Orthopaedic Surgeons) wrote letters to Speaker Nancy Pelosi, House Minority Leader Kevin McCarthy, Senate Majority Leader Mitch McConnell, and Senate Minority Leader Charles Schumer urging the US government to take additional steps to help preserve the viability of physician practices that are suffering steep revenue losses during the COVID-19 pandemic. $^{16}{ }^{17}$ Recommendations included providing direct financial support, grants, and interest-free loans to practices. In addition, a recommendation was made to suspend the current Medicare sequester and postpone payment reductions mandated by the Merit-Based Incentive Payment System program. Other specialties, including family practice and radiology, have also highlighted the significant economic impact of COVID-19 on practices. ${ }^{18} 19$ Specifically, radiology practices are experiencing a 50\%-70\% decrease in imaging volume that is expected to last at least 3-4 months.

Not only is physician practice viability being put at risk, but ASCs are also experiencing economic shortfalls. Moody's Investors (bond credit rating business of Moody's Corporation) either downgraded or put on review to downgrade multiple ASC companies. ${ }^{20} 21$ The ASC companies either downgraded or put on review for downgrade included Surgery Partners, Tenet, HCA Healthcare, and United Health. Tenet furloughed $10 \%$ of its workforce.
While private practices and ASCs suffered negative economic impacts, hospital healthcare systems' financial stability also has been jeopardized by the COVID-19 pandemic. Many large and small healthcare systems have initiated layoffs, hiring freezes, pay cuts, and suspension of retirement contributions. $^{22}{ }^{23}$ Concerns have been raised about the viability of small healthcare systems and possible closures due to the COVID-19 economic consequences. ${ }^{24}$ Many of these healthcare systems have poor financials with limited cash on hand (eg, less than 1 month) to cover salaries and operating costs. The Health Management Associates published an analysis of the financial impact of COVID-19 on Pennsylvania hospitals. The report revealed that in March, Pennsylvania hospital operating margins declined by $\$ 914$ million predominantly due to a loss of revenue related to canceled and deferred services. ${ }^{25}$ The total estimated margin shortfall for Pennsylvania hospitals in 2020 is $\$ 10.2$ billion. Well-respected large healthcare institutions, such as Johns Hopkins University, have also outlined the financial challenges that have resulted from COVID-19. ${ }^{26}$ Employed physicians in multiple healthcare systems have seen a reduction in salaries and bonuses. ${ }^{27}$ This is especially true in systems where physician reimbursement is directly tied to work relative value units. Similarly, this has also occurred in employment contractual relationships that include productivity clauses based on collections and net profits.

\section{SOLUTIONS TO CLINICAL AND ECONOMIC CHALLENGES}

In order to mitigate the economic and clinical challenges resulting from the COVID-19 pandemic, well-thought-out strategic plans and processes must be followed. In the following sections we will provide a framework to survive and potentially flourish during these challenging times.

\section{Telehealth}

Chronic pain presents a variety of challenges to the healthcare system, including a high number of individuals suffering with chronic pain (ie, $40 \%$ of US adults), escalating costs (ie, $\$ 635$ billion annually in the USA), and complex medical management. ${ }^{28}$ Furthermore, these challenges must be met by a limited workforce. ${ }^{28}$ The Association of American Medical Colleges 2017 specialty data report documented 5,435 total active pain physicians, with $93 \%$ of these physicians active in patient care. ${ }^{29}$ Therefore, physician specialist access and travel distance often complicate the ability for patients to receive high-quality pain care. Telemedicine is a viable digital therapy that may help overcome these obstacles.

Prior to the COVID-19 pandemic, the utilization and effectiveness of telemedicine in treating chronic pain had been investigated. Research demonstrated that telemedicine for treating chronic pain improved care access, reduced wait times, decreased costs, and maintained patient satisfaction. ${ }^{30-33}$ These findings have also been replicated in other fields, including emergency medical care, neurology, primary care, headache medicine, and surgery. ${ }^{34-41}$ Telehealth is also beneficial in assisting with biopsychosocial care for patients suffering with pain. ${ }^{42}$

While telehealth has increased in interest and viability as technology has continued to improve, prior to the COVID-19 pandemic its utilization has been deterred by challenges in reimbursement and coverage. However, the COVID-19 pandemic has catapulted the importance of telehealth and rapidly advanced its utilization. As stated, most pain management care falls under the Tier 1 or Tier 2 service classification and thus in-person care has been limited. Telehealth is well versed to meet non-urgent care 


\begin{tabular}{|c|c|c|c|c|}
\hline Service & Description and comments & Requirements & $\begin{array}{l}\text { Common } \\
\text { applicable codes }\end{array}$ & $\begin{array}{l}\text { Medicare average } \\
\text { reimbursement } \\
\text { (non-facility) }\end{array}$ \\
\hline Telehealth visits & $\begin{array}{l}\text { Replace most of the office and hospital visits. } \\
\text { A visit with the provider that uses telecommunications } \\
\text { systems. } \\
\text { Include two-way, real-time, audio-visual devices. }\end{array}$ & $\begin{array}{l}\text { Established. } \\
\text { New patientst. } \\
\text { Communication between the provider and } \\
\text { the patient. } \\
\text { Interactive audio and video } \\
\text { telecommunications. } \\
\text { Real-time communication. }\end{array}$ & $\begin{array}{l}\quad 99201 \\
>\quad 99202 \\
>\quad 99203 \\
>99204 \\
>\quad 99205 \\
>99211 \\
>99212 \\
>99213 \\
>99214 \\
>99215\end{array}$ & $\begin{aligned} & \$ 46.56 \\
& \$ 77.23 \\
& \$ 109.35 \\
& \$ 167.09 \\
& \$ 211.12 \\
& \$ 23.46 \\
= & \$ 46.19 \\
= & \$ 75.16 \\
= & \$ 110.43 \\
> & \$ 148.33\end{aligned}$ \\
\hline $\begin{array}{l}\text { Audio-only E/M } \\
\text { services }\end{array}$ & $\begin{array}{l}\text { A visit with the provider. } \\
\text { Use an audio-only telecommunications system. }\end{array}$ & $\begin{array}{l}\text { Established patient. } \\
\text { New patientst. }\end{array}$ & $\begin{array}{r}\text { - } 99441 \\
-99442 \\
-\quad 99443\end{array}$ & $\begin{aligned} & \$ 14.44 \ddagger \\
> & \$ 28.15 \ddagger \\
> & \$ 41.14 \ddagger\end{aligned}$ \\
\hline Virtual check-in & $\begin{array}{l}\text { Brief technology-based communication service. } \\
\text { A brief check-in with provider via telephone or other } \\
\text { telecommunications device. } \\
\text { Used to decide whether an office visit is necessary (ie, } \\
\text { helps avoid unnecessary visits). } \\
\text { May include a remote evaluation of recorded video } \\
\text { and/or images. } \\
\text { 5-10 min. }\end{array}$ & $\begin{array}{l}\text { Established patient. } \\
\text { Patient-initiated. } \\
\text { Patient verbal consent. } \\
\text { Synchronous exchange. } \\
\text { Exchange of information. } \\
\text { Not related to a medical visit within the } 7 \\
\text { previous days. } \\
\text { Does not lead to a visit within the next } \\
24 \text { hours. }\end{array}$ & $\begin{array}{l}\text { HCPCS G2012 } \\
\text { HCPCS G2010 }\end{array}$ & $\begin{array}{l}\$ 14.80 \\
\$ 12.27\end{array}$ \\
\hline E-visits & $\begin{array}{l}\text { Brief technology-based communication service. } \\
\text { A communication between a patient and a provider } \\
\text { through an online patient portal. } \\
\text { Time-based to include cumulative time over } 7 \text { days. }\end{array}$ & $\begin{array}{l}\text { Established patient. } \\
\text { Patient-initiated. } \\
\text { May occur over a 7-day period. } \\
\text { Patient verbal consent. } \\
\text { - Online patient portal. }\end{array}$ & $\begin{array}{r}> \\
>\quad 99421 \\
>\quad 99422 \\
>\quad 99423\end{array}$ & $\begin{array}{r}\$ 15.52 \\
> \\
\$ 31.04 \\
> \\
\$ 50.16\end{array}$ \\
\hline
\end{tabular}

*Adapted and modified from cms.gov/newsroom/fact-sheets/medicare-telemedicine-health-care-provider-fact-sheet. Accessed April 30, 2020. For Medicare and Medicaid and commercial insurers, please check on coding and billing requirements including modifiers and place of service identification.

†The Department of Health and Human Services, under the 1135 waiver authority and Coronavirus Preparedness and Response Supplemental Appropriations Act, announced a policy of enforcement discretion for Medicare telehealth services and audits will not be conducted to ensure the prior patient relationship requirement exists. ¥Reimbursement prior to the CMS expansion of telehealth on April 30, 2020. ${ }^{51}$

CMS, Centers for Medicare and Medicaid Services; E/M, evaluation and management.

needs during pandemics and global emergencies. ${ }^{43-45}$ In addition, it can help triage patients that need to be seen in care facilities for urgent needs.

Under the Coronavirus Preparedness and Response Supplemental Appropriations Act signed into law on March 6, 2020 and the 1135 waiver authority, CMS significantly improved patient access to virtual care services during the COVID-19 pandemic (table 1). ${ }^{46}$ The new legislation gave the US Department of Health and Human Services (HHS) Secretary the authority to waive numerous telehealth requirements for the duration of the COVID-19 Public Health Emergency (PHE), including the originating site, rural area designation, place of service, Health Insurance Portability and Accountability Act of 1996 (HIPAA)-compliant telecommunication platform, and established patient requirements. Based on reducing the place of service requirement, Medicare beneficiaries can now receive these services in their home. In addition, on March 30, 2020, CMS issued additional emergency declaration blanket waivers for healthcare providers. One of these waivers allows physicians and other practitioners to render telehealth services from their home and bill from their currently enrolled location. ${ }^{47}$ Due to the US HHS waiving potential penalties for healthcare provider HIPAA violations that involve telehealth medical services for patients, everyday communication technologies can be used, including FaceTime, Skype, Facebook messenger video chat, Google Hangouts video, and Zoom. ${ }^{48}$ Strategies that still need to be avoided include public-facing platforms, including Facebook live, Twitch, and TikTok. ${ }^{48}$

CMS also removed some of the telehealth financial barriers and declared that telehealth visits will be paid at the same rate as in-person visits when virtual services are provided with interactive audio and video, real-time communication. On March 17, 2020, the US HHS Office of the Inspector General announced that they waived enforcement of federal penalties for providers who waive beneficiary cost-sharing requirements for federally paid telehealth services during the COVID-19 health emergency. Furthermore, under the interim final rule, CMS finalized separate payments for telephoneonly evaluation and management $(\mathrm{E} / \mathrm{M})$ services (table 1$).{ }^{49}$ However, reimbursement remained a barrier for telephone E/M services and the reimbursement levels did not cover associated overhead costs. The American Society of Regional Anesthesia and Pain Medicine submitted comments to CMS urging the agency to use the authority to waive the video requirement for furnishing $\mathrm{E} / \mathrm{M}$ services via telehealth across all settings and places of services or to increase reimbursement to telephone $\mathrm{E} / \mathrm{M}$ services to bring them in line with office/outpatient in E/M services. ${ }^{50}$ On April 30, 2020, CMS issued additional changes to healthcare, including further expanding telehealth which included increasing payments for audio-only telehealth services to match payments for similar office and outpatient visits. ${ }^{51}$ Table 1 demonstrates the considerable difference in the office/outpatient $\mathrm{E} / \mathrm{M}$ services versus the audio-only $\mathrm{E} / \mathrm{M}$ service codes prior to the April 30 CMS telehealth expansion. 


\section{Remote prescribing}

Due to change in the Drug Enforcement Agency (DEA) policies, the ability to provide patients with controlled substances following a telehealth visit became a possibility. ${ }^{52}$ The DEA lifted prescribing restrictions on treating new and established patients with chronic pain through telehealth during the COVID-19 PHE. On March 20, the DEA announced that telehealth may be used for prescribing controlled substances as long as the following conditions are met by the prescriber: (1) acting within their usual standard of care and the prescription is for a legitimate medical purpose; (2) acting within applicable federal and state laws; and (3) telehealth communication is conducted using real-time, two-way, audio-visual interactive communication system. On March 25, the DEA granted an exception to the requirement that a DEA registrant must be registered in each state in which the practitioner dispenses controlled substances. On March 27, 2020, the DEA broadened the requirements of paper delivery of a prescription of an oral emergency prescription to include photographed and scanned prescriptions. The DEA also expanded practitioners' ability to treat opioid use disorders (OUDs) via telehealth by allowing for the prescription of buprenorphine to new and existing patients with OUD for maintenance and detoxification treatment. ${ }^{52}$ Although many DEA restrictions have been lifted during the COVID-19 PHE, physicians should still follow safe opioid prescribing procedures, including the assessment for an appropriate indication, adequate pain control, adverse events, aberrant behavior, and activities improvement. ${ }^{53}$ The opioid risks and benefits also need to be provided to patients and naloxone should be prescribed when appropriate.

\section{Implementation}

Once the COVID-19 pandemic imposed treatment restrictions, most practices, including the authors, had to move efficiently to implement an effective telehealth service that is financially viable. Steps required included (1) reviewing the telehealth expansion 1135 waiver; (2) analyzing local and national coverage determinations for telehealth; (3) implementing communication strategies, preferably an HIPAA-compliant telehealth service; (4) educating team members on the telehealth process; (5) detailing processes for billing, coding, and collections; and (6) defining processes to assist patients in their understanding of the technology. Although currently non-HIPAA-compliant services can be used, in a survey identifying patient perceptions of telehealth, privacy was identified as a primary concern. ${ }^{35}$ Furthermore, it is critical that staff members educate patients on the practices' telehealth platform. Confidence in telehealth has been shown to positively correlate with a patient's desire to use the relevant technology. ${ }^{54}$ It is also important to remember that many of the waivers and regulations that occurred during the COVID-19 pandemic will likely be reversed or modified. Private insurers may not necessarily follow the CMS policies. Practitioners must continuously monitor legislation and coverage determination policies to remain in compliance. Additionally, the limitations of telehealth must be recognized, and in-person visits need to be considered when telehealth services are inadequate.

The reduction in regulations related to telehealth during the COVID-19 has assisted in meeting the needs of patients with chronic pain in the Tier 1 and Tier 2 classifications. Clearly, the COVID-19 pandemic has accelerated the acceptance of digital medicine. Prior to the pandemic, it was estimated that the value of the telehealth market would be approximately \$36 billion in $2022 .{ }^{44}$
ECONOMIC POLICIES TO MAINTAIN SOLVENCY IN COVID-19

\section{Medical office staffing and management}

With the loss of anticipated recurring revenue, maintaining the financial viability of the medical practice requires a complete analysis of variable and fixed costs. Practices need to maintain financial solvency in order to meet its core mission of providing and maintaining medical care. Unfortunately, in order to maintain this financial solvency, challenging and uncomfortable decisions are often needed. Although a majority of office care would be deemed a Tier 1 or Tier 2 service, high acuity treatment (Tier 3) strategies still need to be in place. Under the CMS framework, a Tier 3 service is defined as when the lack of in-person treatment or service would result in patient harm. In these cases, in-person medical office treatment is an essential service and needs to be available. Medical office patient care is an essential service required for the treatment of emergent and necessary follow-up care.

Since staffing is a variable cost, practices will need to employ new staffing models to decrease overhead. First, to provide care a practice must maintain a leadership staff to monitor and redirect resources and limited clinical and clerical staff to help with clinical daily duties. Staffing not needed based on clinical demands and financial indicators may need to have their schedule hours reduced or furloughed. Since there is the expectation to rehire staff once the situation improves, it is recommended to maintain employee benefits, including health insurance and other benefits. During this downtime, the billing department or service should be redeployed to focus on the collection of accounts receivable, especially older accounts (ie, accounts receivable greater than 30 days). Physician salaries will also need to be adjusted to maintain adequate cash flows and reserves.

\section{Surgery center staffing and management}

Ambulatory surgery centers are authorized by the State Department of Health (DOH) and licensed and regulated by the state. During the COVID-19 pandemic, ASCs are restricted by their respective states' $\mathrm{DOH}$ to perform procedures only for lifesustaining measures. Cases that would fit under the guidelines would include (1) acute infection, (2) acute trauma that would significantly worsen without surgery, (3) potential malignancy, (4) uncontrollable pain that would otherwise require hospital admission, and (5) a condition or prognosis that would significantly worsen with a delay in treatment. The initial decision on whether to keep the ASC open depends on the needs and case mix of the medical staff. Although the caseload in our surgical center (GAB and DAP) has significantly decreased as we follow the $\mathrm{DOH}$ guidelines, we have elected to keep the center open. One reason was that the transition to an increased workload following the removal of ASC restrictions will progress more efficiently than reinitiating operations from a closed ASC. Critical staff including administrative leadership (Director of Operations and Administrative Director) is required. Cross-training of the remaining staff is a necessity. A small amount of staffing will be necessary for building maintenance, inventory management, and medical records. As with the office, the billing department continues to function and focuses on accounts receivable. Staffing is, again, decreased through furloughing and reducing staff hours. Benefits including health insurance are maintained. The Director of Operations provides daily feedback to the $\mathrm{DOH}$ and regional health alliances. Information in the reports includes performed cases and supplying capacity (eg, ventilators) availability to assist with overflow needs. 


\section{GOVERNMENT SUPPORT PROGRAMS AND INSURANCE CONSIDERATIONS}

Although the steps listed above for staffing will assist in mitigating financial losses, many practices will need financial support. Fortunately, government support programs have been put in place to assist with these needs. Recognizing the economic impact on healthcare providers in halting elective medical services during the COVID-19 pandemic, on March 27, 2020, the bipartisan Coronavirus Aid, Relief, and Economic Security Act (CARES Act) was passed providing $\$ 100$ billion in relief funds to hospitals and other healthcare providers. This funding is intended to support healthcare-related expenses or lost revenue attributable to COVID-19. Three areas are relevant to outpatient pain practices and ASCs: (1) Medicare provider distributions-CARES Act Provider Relief Fund; (2) Paycheck Protection Program (PPP) loans; and (3) Accelerated and Advance Payment Program. Although beyond the scope of this article, some states also offer COVID-19 financial assistance programs.

\section{Medicare provider distributions}

A CARES Act funding of $\$ 50$ billion was dedicated to the Provider Relief Fund and was allocated for general distribution to Medicare facilities and providers based on eligible providers' 2018 net patient revenue. ${ }^{55}$ The initial $\$ 30$ billion was distributed between April 10 and April 17, and the remaining \$20 billion began to be distributed on Friday, April 24. The following list summarizes the CARES Act Provider Relief Fund:

- To expedite providers getting money as quickly as possible, $\$ 30$ billion was distributed immediately, proportionate to $6.2 \%$ of providers' Medicare fee-for-service reimbursements in 2019. This simple formula used the data on hand to distribute money to providers as quickly as possible.

- The US HHS began distribution of the remaining \$20 billion of the general distribution to these providers on April 24, allocating money proportional to providers' share of 2018 net patient revenue.

- These funds are not loans and will not have to be repaid. However, providers receiving funds will need to sign an attestation confirming receipt of funds and agree to the terms and conditions of payment and confirm the CMS cost report.

- The terms and conditions of payments require the provider to submit documents enough to ensure that CARES Act funds were used for healthcare-related expenses or lost revenue attributable to coronavirus.

- The portal to sign the online attestation and accept the terms and conditions is now available: https://covid19.linkhealth. com/\#/step/1.

\section{PPP loans}

Established by section 1102 of the CARES Act, the Small Business Association (SBA), in consultation with the Department of the Treasury, developed the PPP. ${ }^{56}$ In summary, the PPP is a loan designed to provide a direct incentive for small business, including pain medicine practices, to keep their workers on the payroll. The following list summarizes the PPP loans:

- Although funding through the PPP is a loan, the SBA will forgive loans if employees are kept on the payroll for 8 weeks following the loan origination and the money is used for payroll, rent, mortgage interest, or utilities.

- Any small business, non-profit organization, sole proprietor, or independent contractor may apply if they employ fewer than 500 per location.
- The non-fee loan will be fully forgiven if the funds are used for payroll costs, interest on mortgages, rent, and utilities, provided that $75 \%$ of the loan amount is used for payroll.

- Loan forgiveness is requested through the lender. The lender must decide on forgiveness within 60 days.

- Loan forgiveness will be reduced if full-time head count declines or if salaries and wages decrease.

- The PPP loan has a maturity of 2 years and an interest fixed rate of $1 \%$. The interest will continue to accrue during the deferment period. The borrow application may be accessed online and processed from the local bank or eligible lender: https://www.sba.gov/document/sba-form--paycheck-protection-program-borrower-application-form.

In our practices, including the ASC, the PPP will assist in the re-employment of staff.

\section{Accelerated and Advance Payment Program}

CMS had expanded an existing Accelerated and Advance Payment Program to a broader group of Medicare providers during the COVID-19 PHE. ${ }^{57}$ This program was previously established to provide expedited payments due to national emergencies or natural disasters to accelerate cash flow to impacted healthcare providers. The following list summarizes the Accelerated Advance Payment Program:

- To qualify, medical practices or providers must have billed Medicare within 180 days prior the request application, not be in bankruptcy, not be under active medical review or investigation, and not have any delinquent Medicare overpayments.

- Providers may request up to $100 \%$ of the Medicare payment amount for a 3-month period.

- Repayment begins 120 days after the date of issuance.

- Accelerated and Advance Payment Program request forms are found on the individual provider's geographic area Medicare Administrative Contractor website.

- On April 26, CMS announced that it is re-evaluating the amounts that will be paid under its Accelerated Payment Program and that it is suspending the Advance Payment Program to part B suppliers including physicians. ${ }^{58}$

While the above government support programs provide much needed funding to see medical practice and providers through the immediate crisis and rehire and retain staff, these programs are not the answer to long-term medical practice survival. A recent survey by the Primary Care Collaborative found an alarming $47 \%$ of practices report being unsure of whether they will be able to remain open due to lack of cash flow. ${ }^{59}$ Additionally, the Medical Group Management Association has surveyed medical practices of all sizes and specialties and found an alarming direct and indirect financial impact of the COVID-19 pandemic, with on average $55 \%$ decrease in revenue since the beginning of the pandemic crisis and a $60 \%$ decrease in volume. ${ }^{60}$ This paints a dire picture not only for independent medical providers, but for the millions of patients who rely on them for their care.

\section{Business interruption insurance}

Business interruption insurance is normally incorporated in most casualty and loss policies carried by medical practices and ASCs. The purpose of the insurance is to compensate an insured for losses due to a slowdown or suspension of its operations. The policy may include coverage for lost revenue and certain expenditures such as rent or lease payments, wages, and loan payments. Traditionally, the insurance generally required physical damage to the property restricting the ability to perform business. 
Recent legislation is being considered in several states to require business interruption insurance to provide coverage for lost revenue during the COVID-19 pandemic. A recent Pennsylvania Supreme Court ruling strengthens the argument for COVID-19 loss coverage. In 'Friends of DeVito vs Wolfe' the court supports the concept that business losses during the pandemic are indistinguishable from those caused by earthquakes, fires and other casualty events for which property-based insurance coverage was intended. ${ }^{61}$ It is important to contact your insurance carrier and gather loss information related to COVID-19. Most likely legislative intervention will be required for successful enforcement of these policies.

\section{STAFF WELL-BEING}

It is critical as leaders of practices and facilities that employee well-being and safety are placed at the forefront. The COVID-19 pandemic has placed unprecedented physical and psychological burden on medical (eg, physicians, nurses) and non-medical (eg, clerical staff, administrators, maintenance workers) healthcare workers. Stressors for staff include personal safety, job security, and essentials such as housing and food. In a recent survey on the psychological impact of the COVID-19 pandemic, non-medical healthcare staff had a higher prevalence of anxiety. ${ }^{62}$ Furthermore, staff well-being promotes safety. Research has demonstrated that poor staff well-being and moderate to high levels of burnout are associated with poor patient safety outcomes including medical errors. ${ }^{63}$ Information and assistance with psychosocial and mental health support systems may be needed.

Staff can be supported in a multitude of ways. First, consistent communication with staff is crucial to deliver effective and clear messages regarding the contemporary status of the workplace as new information about COVID-19 is learned. Furthermore, staff who are furloughed should be encouraged and supported in obtaining resources (eg, unemployment). Efforts should be taken to maintain benefits when possible. Furthermore, it is well known that when individuals are out of work, they can lose their sense of purpose. Therefore, action should be taken to help bring employees back to work as soon as economically feasible. The PPP will assist with this process.

Staff safety is also of the utmost importance. It is incumbent on pain providers to prepare their practice facility and staff for potential exposure to COVID-19. While changes in regulation vary by locality, general recommendations are available to reduce interpersonal COVID-19 exposure, minimize disease transmission, protect healthcare staff and patients, and to preserve healthcare services. Online supplementary appendix 1 displays a sample COVID-19 Office Safety Protocol for an outpatient interventional pain practice.

\section{CONCLUSION}

The COVID-19 pandemic will have short-term and long-lasting implications for all medical practices and facilities. To date, the COVID-19 pandemic has resulted in significant clinical and financial consequences. Medical practices and facilities have been placed under significant financial strain due to state-mandated service restrictions at medical facilities and patient cancellation of appointments due to shelter-in-place and stay-at-home orders. In addition, revenue recovery will become more challenging as patients lose jobs and associated medical insurance coverage. Unfortunately, patients will struggle to pay copays and deductibles that are at all-time highs, thus forcing medical practices to absorb bad debt. Prior to the pandemic, close to one-third of US adults were very worried about one or more types of financial matters. ${ }^{64}$ In addition financial worries have been shown to be significantly associated with chronic spinal pain, a condition often seen in pain clinics. ${ }^{64}$

In order to clinically and financially navigate this pandemic, medical practices will need operational and strategic plans that allow for successful reintegration of clinical and surgical practice. As shelter-in-place orders and stay-at-home orders are modified, practices will have to follow State DOH, CMS, and Centers for Disease Control and Prevention guidelines for safe practice procedures. Unfortunately, the return to normal will most likely not occur until a successful vaccination is implemented or herd immunity is reached. The practice of chronic pain management will be different. Waiting rooms will look vacant as necessary social distancing protocols are implemented. In addition, to compensate for patient flow changes, practices may extend hours of operation, as well as continue to use telehealth. However, medical facilities and practices that adopt new treatment, including technological advancements such as telehealth and staffing paradigms, will be able not only to survive but indeed flourish. Demand for medical and interventional pain care will eventually return. The main mission of all medical practices is to provide high-quality care in a financially viable and cost-efficient manner. This mission has not changed, but the methods to achieve it have been altered since the occurrence of the COVID-19 pandemic.

Contributors DAP, BTS, GAB, and SAF contributed to the design and writing of the manuscript.

Funding The authors have not declared a specific grant for this research from any funding agency in the public, commercial or not-for-profit sectors.

Competing interests DAP has consulted for Avanos, Boston Scientific, Medtronic, Nevro, and Esteve. He has received research support from Avanos, Medtronic, Nevro, Stimgenics, and Abbott. He is an owner of Western PA Surgical Center. GAB is an owner of Western PA Surgical Center.

\section{Patient consent for publication Not required.}

Provenance and peer review Not commissioned; internally peer reviewed.

This article is made freely available for use in accordance with BMJ's website terms and conditions for the duration of the covid-19 pandemic or until otherwise determined by BMJ. You may use, download and print the article for any lawful, non-commercial purpose (including text and data mining) provided that all copyright notices and trade marks are retained.

\section{ORCID iD}

Samuel Ambrose Florentino http://orcid.org/0000-0003-2006-3976

\section{REFERENCES}

1 Rothan HA, Byrareddy SN. The epidemiology and pathogenesis of coronavirus disease (COVID-19) outbreak. J Autoimmun 2020;109:102433.

2 Holshue ML, DeBolt C, Lindquist S, et al. First case of 2019 novel coronavirus in the United States. N Engl J Med 2020;382:929-36.

3 Coronavirus Resource Center. Available: https://coronavirus.jhu.edu/map.html [Accessed 30 Apr 2020].

4 Non-Emergent, Elective Medical Services, and Treatment Recommendations. Available: https://www.cms.gov/files/document/cms-non-emergent-elective-medicalrecommendations.pdf [Accessed 30 Apr 2020].

5 Cohen SP, Baber ZB, Buvanendran A, et al. Pain management best practices from Multispecialty organizations during the COVID-19 pandemic and public health crises. Pain Med 2020. doi:10.1093/pm/pnaa127. [Epub ahead of print: 07 Apr 2020]

6 Shanthanna H, Strand NH, Provenzano DA, et al. Caring for patients with pain during the COVID-19 pandemic: consensus recommendations from an international expert panel. Anaesthesia 2020. doi:10.1111/anae.15076. [Epub ahead of print: $07 \mathrm{Apr}$ 2020].

7 Recommendations on Chronic Pain Practice during the COVID-19 Pandemic. Available: https://www.asra.com/page/2903/recommendations-on-chronic-pain-practice-duringthe-covid-19-pandemic [Accessed 30 Apr 2020].

8 NANS-COVID-ALGORITHM. Available: https://neuromodulation.org/Portals/0/ Webinars/NANS-COVID-ALGORITHM.pdf [Accessed 30 Apr 2020].

9 THE EMPLOYMENT SITUATION. Available: https://www.bls.gov/news.release/pdf/ empsit.pdf [Accessed 30 Apr 2020]. 
10 US weekly jobless claims hit 4.4 million, bringing 5-week total to more than 26 million. Available: https://www.cnbc.com/2020/04/23/weekly-jobless-claims.html [Accessed 30 Apr 2020].

11 A mounting casualty of coronavirus crisis: Health care jobs. Available: https://apnews. com/811b2057ad110605fa70a2745e5e0ee4 [Accessed 30 Apr 2020].

12 COVID-19 Shutters Some Private Practices. Available: https://www.medpagetoday. com/infectiousdisease/covid19/85637 [Accessed 30 Apr 2020].

13 Thousands of US medical workers furloughed, laid off as routine patient visits drop during coronavirus pandemic. Available: https://www.usatoday.com/story/news/ health/2020/04/02/coronavirus-pandemic-jobs-us-health-care-workers-furloughedlaid-off/5102320002/ [Accessed 30 Apr 2020]

14 During a Pandemic, an Unanticipated Problem: Out-of-Work Health Workers. Available: https://www.nytimes.com/2020/04/03/us/politics/coronavirus-health-careworkers-layoffs.html [Accessed 30 Apr 2020].

15 Policy Research Perspectives. Available: https://www.ama-assn.org/system/files/201907/prp-fewer-owners-benchmark-survey-2018.pdf

16 Dear Speaker Pelosi, Leader McConnell, Leader McCarthy, and Leader Schumer. Available: https://searchlf.ama-assn.org/undefined/documentDownload?uri=\% 2Funstructured\%2Fbinary\%2Fletter\%2FLETTERS\%2FAMA-ACP-AAFP-ACS-MGMAFINAL-FOR-DELIVERY.pdf [Accessed 30 Apr 2020].

17 Dear Speaker Pelosi, Leader McConnell, Leader McCarthy, and Leader Schumer. Available: https://searchlf.ama-assn.org/undefined/documentDownload?uri=\% 2Funstructured\%2Fbinary\%2Fletter\%2FLETTERS\%2F2020-3-19-Letter-to-Congressre-Financial-Assistance.pdf [Accessed 30 Apr 2020].

18 Available: https://www.aafp.org/dam/AAFP/documents/advocacy/prevention/crisis/ LT-Congress-COVID4-041320.pdf [Accessed April 30, 2020].

19 Cavallo JJ, Forman HP. The economic impact of the COVID-19 pandemic on radiology practices. Radiology 2020;201495:201495.

20 Available: https://www.moodys.com/ [Accessed 30 Apr 2020]

21 Available: https://www.beckersasc.com/asc-news/pandemic-hit-the-asc-sector-hardbut-it-s-also-ripe-for-recovery-6-updates-from moodys.html?origin=ASCE\&utm_ source=ASCE\&utm_medium=email\&oly_enc_id=3447D1864912B2X [Accessed April 30, 2020].

22 Even nation's largest health systems laying off health care workers amid COVID pandemic. Available: https://abcnews.go.com/Health/coronavirus-victim-americaslargest-health-systems/story?id=70317683 [Accessed 30 Apr 2020].

23 OHSU to cut salaries in reaction to coronavirus downturn, no layoffs for now. Available: oregonlive.com/business/2020/04/ohsu-cuts-salaries-in-reactionto-coronavirus-downturn-no-layoffs-for-now.html?fbclid=IwAR2Prrp70Le1XFzywjyQRql-JOKKtXuZpL3DQYt6ob4yN_dvOincNBwxDg [Accessed 30 Apr 2020].

24 Coronavirus strains cash-strapped hospitals, could cause up to 100 to close within a year. Available: https://www.usatoday.com/story/news/investigations/2020/04/25/ coronavirus-strains-cash-strapped-hospitals-could-cause-mass-closures/2996521001/ [Accessed 30 Apr 2020].

25 Analysis of the Financial Impact of COVID-19 on Pennsylvania Hospitals. Available: https://haponlinecontent.azureedge.net/resourcelibrary/covid-19-financial-impactanalysis-041920.pdf [Accessed 30 Apr 2020].

26 Daniels details financial implications of COVID-19 for the university. Available: https:// hub.jhu.edu/2020/04/21/jhu-prepares-for-financial-challenges-from-covid-19/

27 COVID-19: Employers Cut Doc Pay and Bonuses: What's Your Recourse? Available: https://www.medscape.com/viewarticle/929101\#vp_2 [Accessed 30 Apr 2020].

28 Gaskin DJ, Richard P. The economic costs of pain in the United States. J Pain 2012;13:715-24.

29 Physician Specialty Data Report. Available: https://www.aamc.org/data-reports/ workforce/interactive-data/active-physicians-largest-specialties-2017 [Accessed 30 Apr 2020].

30 Liddy C, Smyth C, Poulin PA, et al. Improving access to chronic pain services through eConsultation: a cross-sectional study of the Champlain base eConsult service. Pain Med 2016;17:pnw038-1057.

31 Hanna GM, Fishman I, Edwards DA, et al. Development and patient satisfaction of a new telemedicine service for pain management at Massachusetts General Hospital to the island of Martha's vineyard. Pain Med 2016;17:1658-63.

32 Theodore BR, Whittington J, Towle C, et al. Transaction cost analysis of in-clinic versus Telehealth consultations for chronic pain: preliminary evidence for rapid and affordable access to interdisciplinary collaborative consultation. Pain Med 2015;16:1045-56.

33 Pronovost A, Peng P, Kern R. Telemedicine in the management of chronic pain: a cost analysis study. Can J Anaesth 2009:56:590-6.

34 Provenzano D, Narouze S. Telemedicine healthcare for headache medicine during COVID-19 and beyond. Ann Head Med 2020;2.
35 Powell RE, Henstenburg JM, Cooper G, et al. Patient perceptions of telehealth primary care video visits. Ann Fam Med 2017;15:225-9.

36 du Toit M, Malau-Aduli B, Vangaveti V, et al. Use of telehealth in the management of non-critical emergencies in rural or remote emergency departments: a systematic review. J Telemed Telecare 2019;25:3-16.

37 Soegaard Ballester JM, Scott MF, Owei L, et al. Patient preference for time-saving telehealth postoperative visits after routine surgery in an urban setting. Surgery 2018;163:672-9.

38 Müller KI, Alstadhaug KB, Bekkelund SI. A randomized trial of telemedicine efficacy and safety for nonacute headaches. Neurology 2017;89:153-62.

39 Müller KI, Alstadhaug KB, Bekkelund SI. Telemedicine in the management of nonacute headaches: a prospective, open-labelled non-inferiority, randomised clinical trial. Cephalalgia 2017;37:855-63.

40 Friedman DI, Rajan B, Seidmann A. A randomized trial of telemedicine for migraine management. Cephalalgia 2019;39:1577-85.

41 Craig JJ, McConville JP, Patterson VH, et al. Neurological examination is possible using telemedicine. J Telemed Telecare 1999:5:177-81.

42 Smith J, Faux SG, Gardner T, et al. Reboot online: a randomized controlled trial comparing an online multidisciplinary pain management program with usual care for chronic pain. Pain Med 2019;20:2385-96.

43 Smith AC, Thomas E, Snoswell CL, et al. Telehealth for global emergencies: implications for coronavirus disease 2019 (COVID-19). J Telemed Telecare 2020;24:x20916567

44 Lurie N, Carr BG. The role of telehealth in the medical response to disasters. JAMA Intern Med 2018;178:745-6

45 Greenhalgh T, Wherton J, Shaw S, et al. Video consultations for covid-19. BMJ 2020;368:m998.

46 Available: cms.gov/newsroom/fact-sheets/medicare-telemedicine-health-careprovider-fact-sheet [Accessed $30 \mathrm{Apr}$ 2020].

47 Available: https://www.cms.gov/files/document/summary-covid-19-emergencydeclaration-waivers.pdf [Accessed April 30, 2020].

48 Available: https://www.hhs.gov/hipaa/for-professionals/special-topics/emergencypreparedness/notification-enforcement-discretion-telehealth/index.html [Accessed April 30, 2020].

49 Available: https://www.cms.gov/files/document/covid-final-ifc.pdf [Accessed April 30, 2020].

50 Available: https://www.asra.com/content/documents/cms_telehealth_0420.pdf [Accessed April 30, 2020].

51 Available: https://www.cms.gov/newsroom/press-releases/trump-administrationissues-second-round-sweeping-changes-support-us-healthcare-system-during-covid [Accessed April 30, 2020].

52 Available: https://www.deadiversion.usdoj.gov/coronavirus.html [Accessed April 30, 2020].

53 Provenzano DA, Viscusi ER. Rethinking the role of opioids in the outpatient management of chronic nonmalignant pain. Curr Med Res Opin 2014;30:2051-62.

54 Edwards L, Thomas C, Gregory A, et al. Are people with chronic diseases interested in using telehealth? A cross-sectional postal survey. J Med Internet Res 2014;16:e123.

55 Available: https://www.hhs.gov/coronavirus/cares-act-provider-relief-fund/index.html [Accessed April 30, 2020].

56 Available: https://home.treasury.gov/system/files/136/PPP-Fact-Sheet.pdf [Accessed April 30, 2020]

57 Available: https://www.cms.gov/files/document/accelerated-and-advanced-paymentsfact-sheet.pdf [Accessed April 30, 2020].

58 Available: https://www.cms.gov/newsroom/press-releases/cms-reevaluatesaccelerated-payment-program-and-suspends-advance-payment-program [Accessed April 30, 2020].

59 Available: https://www.pcpcc.org/2020/04/17/primary-care-practices-endangeredsteep-declines-revenue-and-staff-new-survey-shows [Accessed April 30, 2020].

60 Available: https://www.mgma.com/getattachment/9b8be0c2-0744-41bf-864f04007d6adbd2/2004-G09621D-COVID-Financial-Impact-One-Pager-8-5x11-MW-2. pdf.aspx?lang=en-US\&ext=.pdf [Accessed April 30, 2020].

61 Available: https://cases.justia.com/pennsylvania/supreme-court/2020-68-mm-2020. pdf?ts=1586811868 [Accessed April 30, 2020].

62 Tan BYQ, Chew NWS, Lee GKH, et al. Psychological impact of the COVID-19 pandemic on health care workers in Singapore. Ann Intern Med 2020. doi:10.7326/M20-1083. [Epub ahead of print: 06 Apr 2020].

63 Hall LH, Johnson J, Watt I, et al. Burnout, and patient safety: a systematic review. PLoS One 2016:11:e0159015.

64 Yang $\mathrm{H}$, Haldeman $\mathrm{S}$. Chronic spinal pain and financial worries in the US adult population. Spine 2020:45:528-33. 